\title{
Treponema innocens, a New Species of Intestinal Bacteria, and Emended Description of the Type Strain of Treponema hyodysenteriae Harris et al.
}

\author{
JOANN M. KINYON AND D. L. HARRIS \\ Veterinary Medical Research Institute, College of Veterinary Medicine, Iowa State University, Ames, \\ Iowa 50011
}

\begin{abstract}
Twelve treponemes with serpentine morphology were isolated from pigs and dogs and were compared with strain B78, the type strain of Treponema hyodys. enteriae Harris et al. Nine of the 12 were isolated from cases of swine dysentery, and these were similar in characteristics to strain B78. The three other isolates were not enteropathogenic for swine and could be differentiated from the aforementioned nine isolates on the basis of enteropathogenicity, hemolytic pattern, deoxyribonucleic acid homology, fructose fermentation, and indole production. The morphological and metabolic characters of the 12 isolates and an emended description of strain B78, the type strain of $T$. hyodysenteriae, are presented in this report. Based on these data, the nonpathogenic types are regarded as belonging to a new species, Treponema innocens. The type strain of $T$. innocens is strain B256 (=ATCC 29796).
\end{abstract}

In 1971 Taylor and Alexander (20) isolated two types of treponemes from the colons of pigs with swine dysentery (SD). Isolate A-1 of the first type caused signs and lesions typical of SD when inoculated orally into susceptible pigs. Isolate $\mathrm{A}-1$ produced complete hemolysis on equine blood agar plates and was resistant to tylosin and erythromycin. The isolation of "beta"-hemolytic treponemes in cases of SD was subsequently confirmed $(1,5,6)$. Strain B78 was further characterized and was regarded as a member of a new species, Treponema hyodysenteriae, by Harris et al. (5), who described this organism as follows: weakly gram-negative, loosely coiled, serpentine cells 0.32 to $0.38 \mu \mathrm{m}$ in diameter and 6.0 to $8.5 \mu \mathrm{m}$ long; motile by means of seven to nine axial flagella; hemolytic; anaerobic metabolism; oxidase negative, catalase negative; produced minor amounts of acetic acid from glucose.

Taylor and Alexander's (20) second type of treponemal isolate, designated isolate $4 / 71$, was morphologically identical to isolate A-1 and was present in their source of pigs, which were free of SD. Furthermore, susceptible pigs inoculated with isolate $4 / 71$ remained clinically normal. Isolate $4 / 71$ could be differentiated from isolate A-1 by its "less hemolytic" pattern on blood agar and its susceptibility to tylosin and erythromycin. Recently, the presence of these nonpathogenic types of $T$. hyodysenteriae has been reported in 20 to $40 \%$ of clinically normal swine from eight midwestern U.S. herds (13) and in normal and diarrheic dogs $(12,13)$. Turek and
Meyer observed and cultured a similar treponeme from dogs (21). Hudson et al. have isolated large numbers of this treponeme in cases of postweaning scours in swine (7), and Hunter and Saunders observed these treponemes in postweaning diarrhea of swine and in a dog (9).

Although the pathogenic and nonpathogenic isolates of $T$. hyodysenteriae are morphologically identical $(4,7,13)$ and serologically crossreactive $(7,9 ;$ R. D. Glock, Proc. World Vet. Congr., Thessaloniki, Greece, 1975; L. A. Joens, D. L. Harris, J. M. Kinyon, and M. L. Kaeberle, Congr. Int. Pig Vet. Soc., Ames, Iowa, Abstr. no. L. 8, 1976), they differ with respect to enteropathogenicity $(12,20)$ and hemolysis $(12,20)$ and have low deoxyribonucleic acid (DNA)-DNA homology with each other (R. Miao, A. H. Fieldsteel, and D. L. Harris, Infect. Immun., in press). This report presents biochemical characters which support separation of the nonpathogenic type into a new species.

\section{MATERLALS AND METHODS}

Bacterial strains. The strains used in this study are listed, together with their sources, in Table 1.

Agar media. Bovine blood agar plates with and without spectinomycin (selective isolation medium) were prepared and incubated anaerobically as previously described (18).

Broth media. Trypticase soy broth without glucose (TSB; Baltimore Biological Laboratory, prepared by the anaerobic method (11), supplemented with $10 \%$ fetal calf serum (FCS; Grand Island Biological Co.), inoculated, and incubated under deoxygenated $\mathrm{CO}_{2}$, was the basal medium used in these studies. Methods 
TABLE 1. Pathogenic and nonpathogenic isolates of T. hyodysenteriae used in this study

\begin{tabular}{lccl}
\hline Strain designation $^{a}$ & $\begin{array}{c}\text { Enteropathogenic for } \\
\text { swine }\end{array}$ & Culture collection no. & Clinical characteristic \\
\hline B78 & + & ATCC 27164 & Swine dysentery \\
B140 & + & CCM 6063 & Swine dysentery \\
B153 & + & & Swine dysentery \\
B163 & + & & Swine dysentery \\
B169 & + & & Swine dysentery \\
B204 & + & Swine dysentery \\
B234 & + & ATCC 31212 & Swine dysentery \\
B254 & + & & Swine dysentery \\
B259 & + & & Swine dysentery \\
A-1 & + & & Swine dysentery \\
B256 & - & ATCC 29796 & \\
Puppy & - & & Swine postweaning diarrhea \\
4/71 & - & & Canine catarrhal diarrhea \\
\hline
\end{tabular}

${ }^{a}$ All strains were isolated by us with the exception of A-1 and 4/71, which were kindly supplied by D. J. Taylor, University of Glasgow, Glasgow, Scotland.

${ }^{b}$ CCM, Czechoslovak Collection of Microorganisms, Brno, Czechoslovakia.

of preparation, inoculation, and scoring test results were based on the methods presented in the Anaerobe Laboratory Manual (10), with the major exception of TSB-FCS as the basal medium rather than peptone yeast broth. Other exceptions were as follows.

(i) Esculin hydrolysis. TSB-esculin was supplemented with only $0.5 \%$ FCS since $10 \%$ FCS completely hydrolyzed esculin. The amount of esculin hydrolysis in cultures was determined by serial dilution of inoculated and uninoculated media after 4,6 , and 8 days of incubation. Reagent was immediately added to each dilution and the reaction was recorded (black color indicated hydrolysis). Esculin hydrolysis in uninoculated media and in esculin-negative cultures was observed only in the undiluted broth, whereas esculinpositive cultures produced hydrolysis at a dilution of 1:8.

(ii) Sodium hippurate. For the detection of hippurate hydrolysis, $1 \%$ sodium hippurate was added to TSB-FCS. An uninoculated control was set up with each inoculated TSB-FCS-hippurate culture. After the incubation period, $1-\mathrm{ml}$ amounts of uninoculated control medium were titrated with $0.1,0.2,0.3,0.4,0.5$, 0.6 , or $0.7 \mathrm{ml}$ of sodium hippurate reagent (ferric chloride). The minimum amount of reagent (usually 0.5 or $0.6 \mathrm{ml}$ ) which resulted in a clear uninoculated control was added to the culture. The presence of a brown precipitate was recorded as hydrolysis.

(iii) $\mathbf{~ p H}$. The $\mathrm{pH}$ of incubated uninoculated media under $\mathrm{CO}_{2}$ was $6.2 \pm 0.2$. Cultures were recorded as positive for acid production from a given carbohydrate if the $\mathrm{pH}$ was at least 0.25 unit lower than the $\mathrm{pH}$ of uninoculated media. The typical acid reaction in glucose was 5.9 .

Hemolysis. Isolates were described and recorded as beta-hemolytic or "weakly beta"-hemolytic $(12,20)$. The beta-hemolytic reaction associated with pathogenic strains of $T$. hyodysenteriae has a discrete, defined edge and usually is readily apparent after 2 to 4 days of incubation. The weakly beta reaction associated with nonpathogenic strains of $T$. hyodysenteriae is less intense, has a poorly defined edge, and fre- quently is not apparent until after 6 days of incubation. Both organisms are usually macroscopically evident only by the hemolysis they produce. The surface growth of young cultures is in the form of a slight film usually without individual, distinct colonies.

Gas chromatography. Cultures of the isolates in TSB-FCS, in TSB-FCS-glucose, -frutose, or -maltose, and in TSB-FCS-lactate, -pyruvate, and -threonine were analyzed for the production of alcohols, volatile fatty acids, and nonvolatile fatty acids by the method described by Holdeman et al. (10) by use of a Varian Aerograph (Varian Aerograph, Walnut Creek, Calif.) thermal conductivity gas chromatograph.

Uninoculated control media, TSB-FCS, and TSBFCS-glucose were also analyzed and found to contain acetic and lactic acids. Peak heights of uninoculated control media were subtracted from peak heights of cultures in TSB-FCS and TSB-FCS-glucose. Peak heights of lactic and pyruvic acids in cultures of organisms in TSB-FCS-lactate or -pyruvate were compared with uninoculated control media. Disappearance of lactate and pyruvate were recorded as utilization of the fatty acid substrate by cultures.

Conversion of threonine to propionic acid was determined by comparison of propionic acid peaks from culture in TSB-FCS-threonine with those from culture in TSB-FCS.

Gaseous products of the isolates were analyzed by gas chromatography by injecting atmospheres above TSB-FCS cultures (grown under deoxygenated, prepurified $\mathrm{N}_{2}$ ) into a GC-2A gas chromatograph (Beckman) and a respiration and blood gas analyzer (Loenco). The Beckman instrument was operated at a column temperature of $40^{\circ} \mathrm{C}$ and a detector current of $150 \mathrm{~mA}$ and with a stainless-steel column (6 feet [ca. $183 \mathrm{~cm}$ ] long, 0.25 inch [ca. $0.64 \mathrm{~cm}$ ] in diameter) packed with silica gel and with argon as carrier gas. It detected $\mathrm{H}_{2}$ and $\mathrm{N}_{2}$. The Loenco instrument (model AD 2000) was operated at a column temperature of $53^{\circ} \mathrm{C}$ and a detector current of $150 \mathrm{~mA}$, with helium as the carrier gas. This analyzer had two columns separated by a $\mathrm{CO}_{2}$ stripper with a detector at the end 
of each column. The first column (3-foot [ca. 91-cm]long, 0.25-inch-diameter aluminum) was packed with 80-100-mesh Poropak $Q$ and detected both a composite peak of all gases except $\mathrm{CO}_{2}$ and a $\mathrm{CO}_{2}$ peak. The second column (12-foot[ca. 336-cm]-long, 0.25-inch-diameter aluminum) was packed with a 30-60-mesh molecular sieve and separated $\mathrm{O}_{2}, \mathrm{~N}_{2}$, and $\mathrm{CO}$.

A tuberculin syringe was used to obtain and inject the samples. It was rinsed with $\mathbf{N}_{2}$ before insertion through the stoppers of culture tubes, rinsed five times with the atmosphere above cultures, and withdrawn with $800 \mu \mathrm{l}$ of gas. Three-hundred-microliter samples were injected after the needle had been flushed with the excess atmosphere in the syringe. Peaks were identified according to retention time as compared with standards of pure and mixed-gas standards injected daily. Atmospheres above uninoculated control TSB supplemented with FCS contained no $\mathrm{H}_{2}$ and small quantities of $\mathrm{CO}_{2}$.

Enteropathogenicity. The method of testing for the enteropathogenicity of these isolates has been previously reported (12). At the time of that report, $T$. hyodysenteriae strain B259 (beta-hemolytic) had not produced SD in either of two pigs inoculated in a single attempt to determine enteropathogenicity. In a subsequent trial using higher numbers of the organism $\left(102 \times 10^{9}\right.$ colony-forming units/pig compared to 1.8 $\times 10^{9}$ in the previous trial), isolate B259 produced typical signs and lesions of SD in the two pigs inoculated.

Electron microscopy. Electron microscope observations of phosphotungstic acid-negative stains were made on a Hitachi Hu-11A electron microscope at 50 $k V$. Contact prints of photomicrographs were used to determine cell dimensions and to count axial flagella. Student's $t$ test (18) was used to statistically analyze the data.

Cells for electron microscope observation were harvested with phosphate-buffered saline $(0.01 \mathrm{M}, \mathrm{pH}$ 7.4) from blood agar plate cultures, from aerobically prepared TSB-FCS (11), or from anaerobically prepared TSB-FCS. The cells were centrifuged for $30 \mathrm{~min}$ at $10,000 \times g$. They were then suspended in distilled water and mixed in the ratio 6:5:1 with $2.5 \%$ phosphotungstic acid (neutralized with $\mathrm{KOH}$ ) and $2 \%$ bovine serum albumin (Cohn fraction V; Sigma Chemical Co., St. Louis, Mo.). This mixture was incubated at room temperature for $15 \mathrm{~min}$ and was then transferred to a glass nebulizer. The nebulizer was held 2 to $5 \mathrm{~cm}$ in front of a Formvar (Vaughn, Inc., Memphis, Tenn.)coated, 100-mesh copper grid and sprayed two to three times. Grids were examined immediately.

\section{RESULTS}

All pathogenic isolates of $T$. hyodysenteriae were beta-hemolytic, whereas all nonpathogenic isolates were weakly beta-hemolytic (see Fig. 1). Hemolytic patterns did not change after repeated laboratory passage.

Thirteen isolates (10 pathogenic and 3 nonpathogenic) were compared in 37 phenotypic characteristics. All isolates were positive for growth in bile, growth at $42^{\circ} \mathrm{C}$, growth at $37^{\circ} \mathrm{C}$, and motility. All isolates were negative for es-

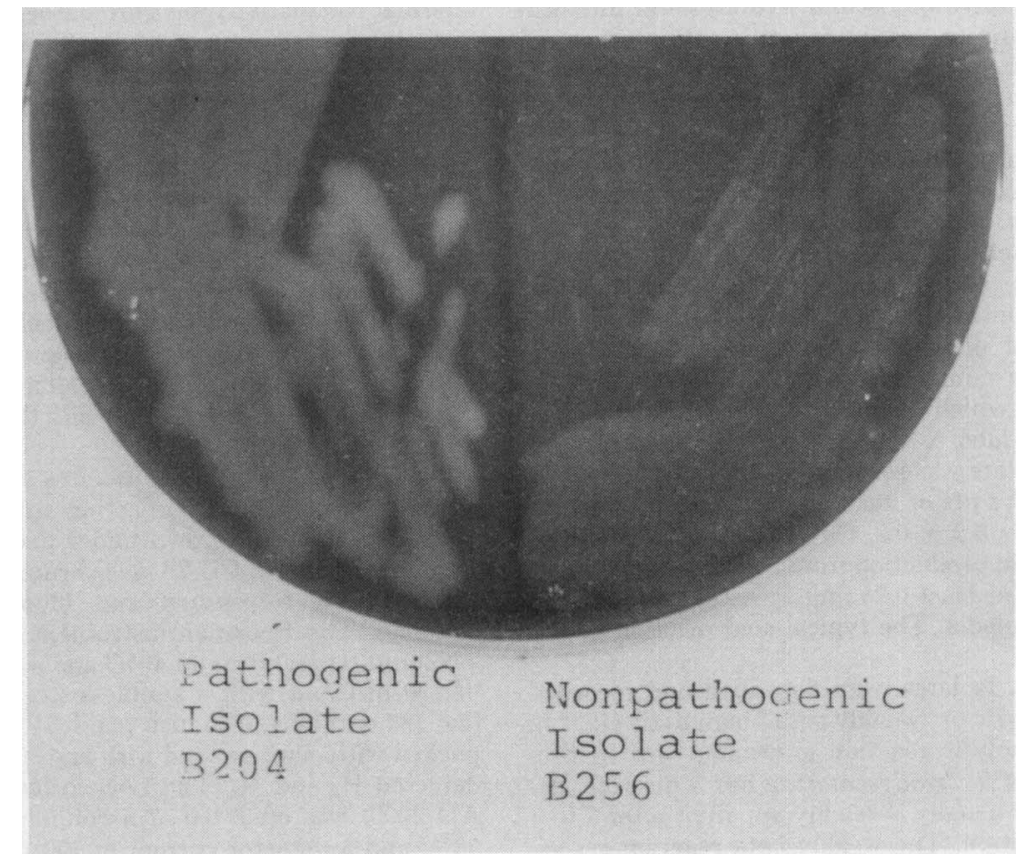

Fig. 1. Beta-hemolytic pattern of a pathogenic isolate (B204) of T. hyodysenteriae compared to that of a nonpathogenic isolate (B256) of T. hyodysenteriae. 
culin, sucrose, and mannitol fermentation; lecithinase, lipase, oxidase, catalase, urease, and acetymethylcarbinol production; and for growth at 25 and $30^{\circ} \mathrm{C}$ and in the presence of $1 \%$ glycine. Characteristics which varied from isolate to isolate are presented in Table 2.

Essentially all isolates were positive for pyruvate utilization and iodoacetate tolerance and negative for gelatin and hippurate hydrolysis, $\mathrm{H}_{2} \mathrm{~S}$ production, nitrate reduction, and lactate utilization. Four characteristics (also presented in Table 2)-enteropathogenicity, hemolytic pattern, fructose fermentation, and indole production-are useful in separating pathogenic from nonpathogenic isolates of $T$. hyodysenter. iae.

All of the isolates studied produced minor amounts of acetic and butyric acids. Occasionally, unidentified alcohols were detected in isolates B140, Puppy, and 4/71. All pathogenic and nonpathogenic $T$. hyodysenteriae isolates produced moderate quantities of both $\mathrm{H}_{2}$ and $\mathrm{CO}_{2}$ as determined by gas chromatographic analysis of the atmosphere above the cultures.

Morphologically, pathogenic and nonpathogenic isolates of $T$. hyodysenteriae appear very similar. The results of electron microscope measurements are presented in Table 3. There were no statistically significant differences between the cell sizes of pathogenic and nonpathogenic strains of $T$. hyodysenteriae in negatively stained electron microscope preparations. Pathogenic isolate B204 and nonpathogenic isolate B256 appeared identical when carbol fuchsinstained cells of each were examined by light microscopy (see Fig. 2 and 3).

\section{DISCUSSION}

The role of $T$. hyodysenteriae in the etiology of SD has been recognized, and the enterpathogenicity of isolates for conventional, specificpathogen-free (12), and gnotobiotic (2) swine has been widely reported $(1,3,5,8,12,20)$. This increased awareness of the importance of $T$. hyodysenteriae in SD has brought about a change in the techniques used for diagnosis of the disease. Establishment of the presence of the causative agent (pathogenic type of $T$. hyodysenteriae) by any of several techniques $(4,13,15)$ is recommended. The most reliable technique is selective isolation and identification of the organism because of the ubiquitous nature of the morphologically similar, indigenous, nonpathogenic type of $T$. hyodysenteriae. Both pathogens and nonpathogens grow on TSA-S400 selective medium. The nonpathogens are normally present in very low numbers $\left(10^{2}\right.$ to $10^{4}$ colony-forming units/g) in the intestinal contents and tissue of swine (13). However, Hudson et al., using specific antisera in a fluorescent-antibody test, have noted increased numbers of these organisms in swine experiencing diarrhea unrelated to swine dysentery (7). This is diagnostically important since increased numbers of pathogenic types of $T$. hyodysenteriae are observed in the feces of swine showing the first clinical symptoms (diarrhea) of SD $(8,12)$.

A similar situation exists in dogs in that in addition to the reported isolation of nonpathogenic types $(12,13,21)$, it has been recently reported that dogs may serve as carrier animals for $T$. hyodysenteriae (17). These facts make the separation of the pathogenic and nonpathogenic isolates of $T$. hyodysenteriae of the utmost importance.

Both pathogenic and nonpathogenic $T$. hy odysenteriae isolates are members of the order Spirochaetales and family Spirochaetaceae (flexuous, helically coiled cells with serpentine motility and with a protoplasmic cylinder with axial fibrils and an outer envelope) (16). They are included in the genus Treponema by virtue of their size (5 to $15 \mu \mathrm{m}$ long and 0.09 to $0.5 \mu \mathrm{m}$ wide), anaerobic metabolism, and lack of catalase and oxidase. Other genera in the family include the leptospiras, which are aerobic, the borrelias, which are transmitted by ticks and lice, the cristispiras, which are very large (30 to $150 \mu \mathrm{m}$ long) and have more than 100 axial fibrils, and the spirochetas, which are free-living.

According to the information in Bergey's Manual (16), pathogenic and nonpathogenic $T$. hyodysenteriae isolates can be differentiated from $T$. phagedenis because the latter ferments mannitol and produces propionic acid and several alcohols in addition to acetic and butyric acids. Treponema macrodentium produces lactic, acetic, formic, and succinic acids, which differentiates it from pathogenic and nonpathogenic $T$. hyodysenteriae isolates (both produce acetic and butyric acids). Separation of the species in the genus according to the Anaerobe Laboratory Manual (10) places pathogenic and nonpathogenic $T$. hyodysenteriae isolates with $T$. phagedenis biovar kazan, T. macrodentium, and $T$. oralis (all hydrolyze esculin). Separation of these isolates from $T$. phagedenis biovar $k a$ zan is based on the mannitol fermentation reaction and products from glucose, whereas separation from $T$. macrodentium is based on sucrose fermentation and products from glucose. Finally, $T$. oralis digests gelatin, whereas pathogenic and nonpathogenic isolates of $T$. hyodysenteriae do not.

The DNAs of both pathogenic and nonpathogenic isolates of $T$. hyodysenteriae have low guanine-plus-cytosine contents (25.7 to 25.9 


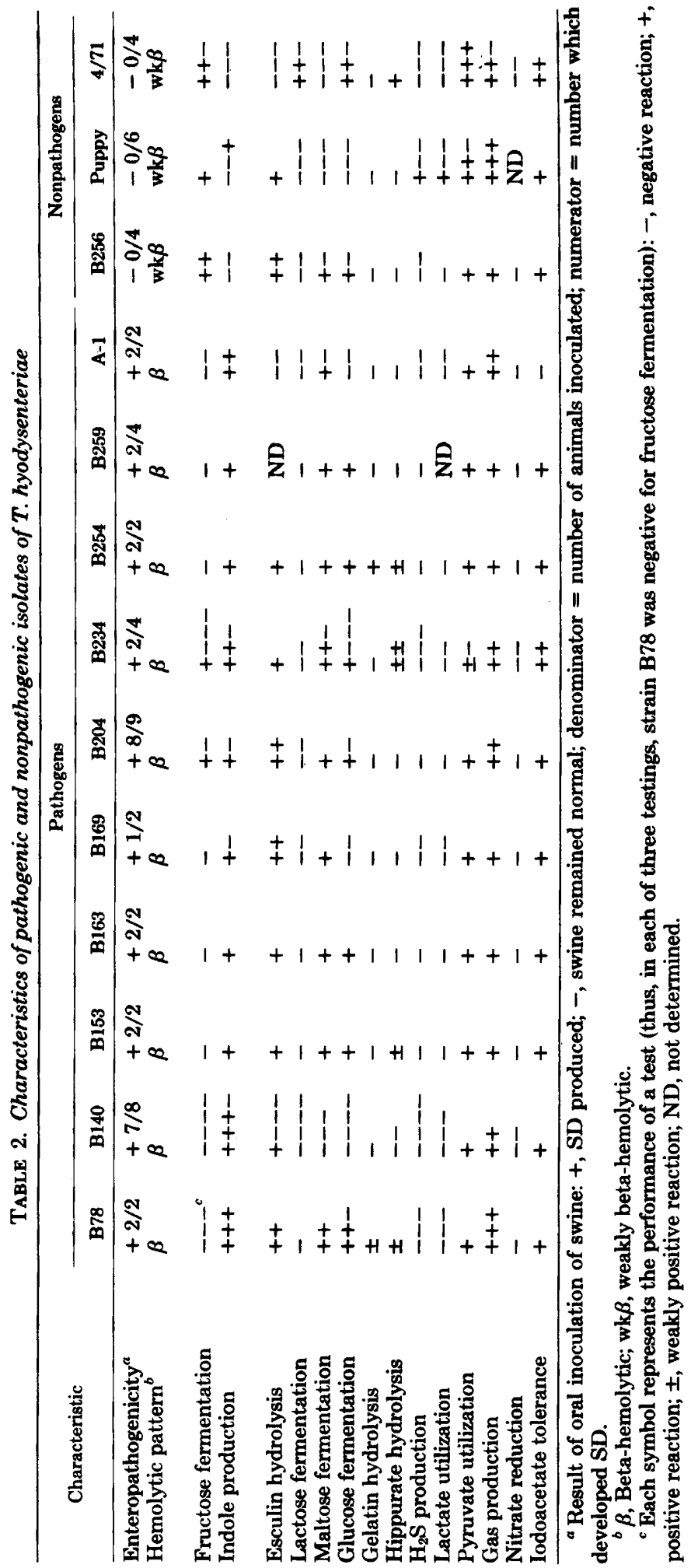


TABLE 3. Measurements of cells of pathogenic and nonpathogenic $T$. hyodysenteriae isolates ${ }^{a}$

\begin{tabular}{|c|c|c|c|c|c|c|c|c|}
\hline \multirow{2}{*}{ Strain } & \multirow{2}{*}{ Passage } & \multirow{2}{*}{$\begin{array}{l}\text { Culture }^{b} \\
\text { medium }\end{array}$} & \multicolumn{2}{|c|}{ Diam (nm) } & \multicolumn{2}{|c|}{ Length $(\mu \mathrm{m})$} & \multicolumn{2}{|c|}{ No. of axial flagella } \\
\hline & & & Mean & Range & Mean & Range & Mean & Range \\
\hline$\overline{\mathrm{B} 78}$ & 70 & $\mathbf{A}$ & 305 & $233-449(10)^{c}$ & 8.9 & $8.3-9.8(4)^{c}$ & $8-9$ & $\overline{7-10(9)^{c}}$ \\
\hline B140 & 15 & $\mathbf{A}$ & 392 & $298-501(7)$ & 10.4 & $7.6-14.3(3)$ & $7-8$ & $7-11(11)$ \\
\hline $\mathrm{B} 153$ & 10 & C & 321 & $313-346(4)$ & 8.0 & $7.7-8.3(2)$ & $8-9$ & $7-9(5)$ \\
\hline $\mathrm{B163}$ & 11 & $\mathbf{B}$ & 308 & $242-355(8)$ & 6.5 & $5.6-8.2(5)$ & $8-9$ & $7-10(4)$ \\
\hline B169 & 11 & $\mathbf{A}$ & 414 & $383-445(6)$ & 7.6 & $6.4-9.7(5)$ & $8-9$ & $7-10(10)$ \\
\hline B204 & 8 & $\mathbf{B}$ & 336 & $244-374(6)$ & 8.6 & $5.9-10.5(4)$ & 8-9 & $7-10(10)$ \\
\hline B234 & 10 & B & 357 & $250-473(5)$ & 8.3 & $7.8-9.0(4)$ & $7-8$ & $7-9(8)$ \\
\hline B254 & 10 & $\mathrm{C}$ & 265 & $200-307(6)$ & 6.2 & $3.8-8.2(3)$ & 9 & $6-10(11)$ \\
\hline B259 & 8 & C & 292 & $212-361(6)$ & 8.4 & $6.6-9.2(4)$ & $7-8$ & $7-9(5)$ \\
\hline A-1 & 5 & B & 303 & $276-317(4)$ & 10.9 & $8.7-15.0(3)$ & $10-11$ & $9-12(2)$ \\
\hline Mean & & & 329 & & 8.4 & & $8-9$ & \\
\hline $\mathrm{B} 256$ & 13 & B & 362 & $313-401(7)$ & 8.8 & $7.4-14.1(7)$ & 9 & $7-10(8)$ \\
\hline Puppy & 8 & $\mathbf{A}$ & 282 & $208-314$ (4) & 6.1 & $5.6-6.5(2)$ & $5-6$ & 4-7(7) \\
\hline $4 / 71$ & 7 & C & 334 & $288-365(4)$ & 6.3 & $5.3-7.4(4)$ & $12-13$ & $10-14(5)$ \\
\hline Mean & & & 326 & & 7.0 & & 8 & \\
\hline
\end{tabular}

${ }^{a}$ Measurements were made from electron micrographs.

${ }^{b}$ Isolates were grown in pure culture in: A, aerobically prepared TSB; B, anaerobically prepared TSB with $10 \%$ FCS under $\mathrm{H}_{2}-\mathrm{CO}_{2}$; or C, Trypticase soy agar with blood.

${ }^{c}$ Number in parentheses is number of observations.

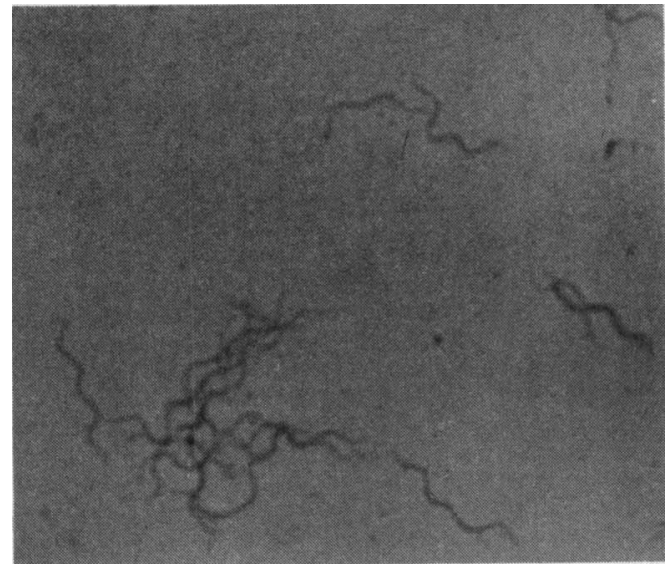

Fig. 2. Carbol fuchsin-stained preparation of a pathogenic isolate (B204) of T. hyodysenteriae.

mol\%), as measured by thermal denaturation. In addition, they share a low level of DNA sequence homology $(21 \%)$, which places them within the same genus but in different species (Miao et al., in press). The guanine-plus-cytosine ratios of these isolates are considerably lower than those reported for the other treponemes (37 to 52 mol\%) $(14,16)$.

Pathogenic $T$. hyodysenteriae isolates are enteropathogenic for swine and are beta-hemolytic, indole positive, and fructose fermentation negative. Nonpathogenic $T$. hyodysenteriae iso-



FIG. 3. Carbol fuchsin-stained preparation of a nonpathogenic isolate (B256) of $T$. hyodysenteriae.

lates do not produce disease in swine and are weakly beta-hemolytic, indole negative, and fructose fermentation positive. The most reliable of these characteristics, enteropathogenicity, directly correlates with hemolytic pattern. Indole production and fructose fermentation have been somewhat variable but should prove helpful in the separation of the pathogenic from the nonpathogenic isolates. 
Based on the differences in enteropathogenicity $(12,20)$, hemolytic pattern $(12,20)$, DNADNA homology (Miao et al., in press), and biochemical characteristics presented in this report, we regard the nonpathogenic strains of $T$. $h y$ odysenteriae (previously referred to as nonpathogenic types of $T$. hyodysenteriae [12, 13], postweaning scour spirochetes [7, 9], and canine spirochetes $[3,21]$ as members of a distinct, new species, for which we propose the name Treponema innocens (iń no.cens. L. adj. innocens doing no harm). The type strain of $T$. innocens is strain $\mathrm{B} 256$.

$T$. innocens sp. nov. Gram-negative, serpentine cells with two to three turns per cell and eight or nine axial flagella; the cells measure approximately $326 \mathrm{~nm}$ in width and $7.0 \mu \mathrm{m}$ in length. Positive for: growth in bile and iodoacetate; growth at 42 and $37^{\circ} \mathrm{C}$; production of $\mathrm{H}_{2}$, $\mathrm{CO}_{2}$, acetic acid, and butyric acid; and utilization of fructose and pyruvate. Negative for: the fermentation of esculin, sucrose, and mannitol; lecithinase, lipase, oxidase, catalase, urease, acetylmethylcarbinol, indole, and $\mathrm{H}_{2} \mathrm{~S}$ production; gelatin and hippurate hydrolysis; lactate utilization; nitrate reduction; and growth at 25 and $30^{\circ} \mathrm{C}$ and in the presence of $1 \%$ glycine. The three isolates so far included in the species reacted variably with respect to esculin hydrolysis and lactose, maltose, and glucose fermentation (see Table 2). Hemolytic (but less than T. hyodysenteriae). Not pathogenic when orally inoculated into swine. Known to be present in the intestinal contents and feces of swine and dogs. The type strain is strain B256. A culture of this strain has been deposited in the American Type Culture Collection under the number 29796.

Description of the type strain of $T$. innocens. Gram-negative cells $362 \mathrm{~nm}$ in diameter and $8.8 \mu \mathrm{m}$ in length. Serpentine motility by means of nine axial flagella. Positive for: growth in bile and iodoacetate; growth at 42 and $37^{\circ} \mathrm{C}$; fructose, maltose, and glucose fermentation; pyruvate utilization; $\mathrm{H}_{2}$ and $\mathrm{CO}_{2}$ production; and esculin hydrolysis. Produces acetic and butyric acids from glucose. Negative for: esculin, sucrose, lactose, and mannitol fermentation; lecithinase, lipase, oxidase, catalase, urease, acetylmethylcarbinol, indole, and $\mathrm{H}_{2} \mathrm{~S}$ production; gelatin and hippurate hydrolysis; lactate utilization; nitrate reduction; and growth at 25 and $30^{\circ} \mathrm{C}$ and in the presence of $1 \%$ glycine. Weakly betahemolytic. Not enteropathogenic for swine.

The emended description of strain B78 (=ATCC 27164), the type strain of $T$. hyodysenteriae, is as follows: gram-negative cells which measure $305 \mathrm{~nm}$ in diameter and $8.9 \mu \mathrm{m}$ in length. Serpentine motility by means of eight to nine axial flagella. Positive for: growth in bile and at 42 and $37^{\circ} \mathrm{C}$; iodoacetate tolerance; $\mathrm{H}_{2}$, $\mathrm{CO}_{2}$, and indole production; pyruvate utilization; glucose and maltose fermentation; and esculin hydrolysis. Volatile fatty acid products of fermentation from glucose were acetic and butyric acids. Negative for: esculin, sucrose, lactose, fructose, and mannitol fermentation; lecithinase, lipase, oxidase, catalase, urease, $\mathrm{H}_{2} \mathrm{~S}$, and acetylmethylcarbinol production; growth at 25 and $30^{\circ} \mathrm{C}$ and in the presence of $1 \%$ glycine; nitrate reduction; and lactate utilization. Gelatin and hippurate were weakly hydrolyzed. Beta-hemolytic. Enteropathogenic for swine.

The isolates of $T$. innocens used in this study were from both dog and pig sources and were similar with respect to lack of enteropathogenicity, hemolytic pattern, morphology, and metabolic characteristics. Turek and Meyer (21) recently reported the isolation of a treponeme (from the intestines of dogs) which apparently produces hemolysis similar to the nonpathogenic isolates used in this report. However, their isolate has a smaller diameter and fewer axial fibrils than our isolates. The specific end structure observed on Turek's organisms have also been observed on T. innocens from both dog and pig sources (A. E. Ritchie, J. M. Kinyon, and I. M. Robinson, unpublished data). Further comparison of phenotypic characteristics are needed to resolve the taxonomic position of Turek's organism.

\section{ACKNOWLEDGMENTS}

This investigation was supported by grants from the National Pork Producers Council; the U.S. Department of Agriculture (grant 12-14-3991-291 from the National Animal Disease Center), and the Public Health Service (grant A112129 from the National Institute of Allergy and Infectious Diseases).

We acknowledge the capable technical assistance of Carol Bell and Carol Toussaint. Special thanks are extended to John G. Holt, Department of Bacteriology, Iowa State University, Ames, Iowa, and Thomas O. Macadoo, Department of Foreign Languages, Virginia Polytechnic Institute and State University, Blacksburg, $\mathrm{Va}$., for assistance in selecting a name for this organism. Special thanks are also due to Raymond Miao for sharing his data regarding guanine-plus-cytosine ratios and DNA-DNA homologies.

\section{REPRINT REQUESTS}

Address reprint requests to: Ms. Joann M. Kinyon, Veterinary Medical Research Institute, Building 3, Iowa State University, Ames, IA 50011.

\section{LITERATURE CITED}

1. Glock, R. D., and D. L. Harris. 1972. Swine dysentery. II. Characterization of lesions in pigs inoculated with Treponema hyodysenteriae in pure and mixed cultures. Vet. Med. Small Anim. Clin. 67:65-68.

2. Harris, D. L., T. J. L. Alexander, S. C. Whipp, I. M. Robinson, R. D. Glock, and P. J. Matthews. 1978. Swine dysentery: studies of gnotobiotic pigs inoculated with Treponema hyodysenteriae, Bacteroides vulgatus, 
and Fusobacterium necrophorum. J. Am. Vet. Med. Assoc. 172:468-471.

3. Harris, D. L., R. D. Glock, C. R. Christensen, and J. M. Kinyon. 1972. Swine dysentery I. Inoculation of pigs with Treponema hyodysenteriae (new species) and reproduction of the disesse. Vet. Med. Small Anim. Clin. 67:61-64.

4. Harris, D. L., and J. M Kinyon. 1974. Significance of anaerobic spirochetes in the intestines of animals. Am. J. Clin. Nutr. 27:1297-1304.

5. Harris, D. L., J. M. Kinyon, M. T. Mullin, and R. D. Glock. 1972. Isolation and propagation of spirochetes from the colon of swine dysentery affected pigs. Can. J. Comp. Med. 36:74-76.

6. Harris, D. L., J. M. Kinyon, J. G. Songer, and R. D. Glock. 1976. Diagnosis of swine dysentery by culture. Feedstuffs 48:28

7. Hudson, M. J., T. J. L. Alexander, and R. J. Lysons. 1976. Diagnosis of swine dysentery: spirochaetes which may be confused with Treponema hyodysenteriae. Vet. Rec. 99:498-500.

8. Hughes, R., H. J. Olander, D. L. Kanitz, and S. Qureshi. 1977. A study of swine dysentery by immunofluorescence and histology. Vet. Pathol. 14:490-507.

9. Hunter, D., and C. N. Saunders. 1977. Diagnosis of swine dysentery using absorbed fluorescent antiserum. Vet. Rec. 101:303-304.

10. Holdeman, L. V., E. P. Cato, and W. E. C. Moore (ed.). 1977. Anaerobe laboratory manual, 4th ed. Virginia Polytechnic Institute and State University, Anaerobe Laboratory, Blacksburg.

11. Kinyon, J. M., and D. L. Harris. 1974. Growth of Tre ponema hyodysenteriae in liquid medium. Vet. Rec. 95: 219-220.

12. Kinyon, J. M., D. L. Harris, and R. D. Glock. 1977.
Enteropathogenicity of various isolates of Treponema hyodysenteriae. Infect. Immun. 15:638-646.

13. Kinyon, J. M., J. G. Songer, M. Janc, and D. L. Harris. 1976. Isolation and identification of Treponema hyodysenteriae: aid to the diagnosis and treatment of swine dysentery. Proc. Am. Assoc. Vet. Lab. Diag. 1976: 65-74.

14. Miao, R., and A. H. Fieldsteel. 1978. Genetics of Tre ponema: relationship between Treponema pallidum and five cultivable treponemes. J. Bacteriol. 133:101107.

15. Olson, L. D. 1978. Staining large spirochetes in fecal and colonic scrapings with Victoria blue 4-R: an aid in the diagnosis of swine dysentery. Vet. Med. Small Anim. Clin. 73:80.

16. Smibert, R. A. 1974. Order I. Spirochaetales; genus III. Treponema, p. 175-184. In R. E. Buchanan and N. E Gibbons (eds.), Bergey's manual of determinative bacteriology, 8th ed. The Williams Wilkins Co., Baltimore.

17. Songer, J. G., R. D. Glock, K. J. Schwartz, and D. L. Harris. 1978. Isolation of Treponema hyodysenteriae from sources other than swine. J. Am. Vet. Med. Assoc. 172:464-466.

18. Songer, J. G., J. M. Kinyon, and D. L. Harris. 1976. Selective medium for isolation of Treponema hyodys. enteriae. J. Clin. Microbiol. 4:57-60.

19. Steel, R. G. D., and J. H. Torrie. 1960. Principles and procedures of statistics, 1st ed. McGraw-Hill Book Co., Inc., New York.

20. Taylor, D. J., and T. J. L. Alexander. 1971. The production of dysentery in swine by feeding cultures containing a spirochaete. Br. Vet. J. 127:58-61.

21. Turek, J. J., and R. C. Meyer. 1977. Diagnosis of swine dysentery using spirochaete I. Its isolation, cultivation, and ultrastructure. Can. J. Comp. Med. 41:332-337. 